\title{
The Bergen Social Media Addiction Scale Validity in a Romanian Sample Using Item Response Theory and Network Analysis
}

\section{Elena Stănculescu ${ }^{1}$}

Accepted: 6 December 2021

(C) The Author(s), under exclusive licence to Springer Science+Business Media, LLC, part of Springer Nature 2021

\begin{abstract}
The validation of the Bergen Social Media Addiction Scale (BSMAS) in different cultural contexts is contributory in adding to the extant research body on psychometric qualities of the scale. The main purpose of this study was to examine the validity of the BSMAS, based on classical test theory and advanced psychometric testing, namely item response theory (IRT) and network analysis in a Romanian sample of 705 participants (39\% males, aged 18-54 years, $M=30.24, S D \pm 9.15$ ). Composite reliability and McDonald's omega proved the very good internal consistency of the BSMAS-RO. The CFA highlighted the unifactorial model fitted well and measurement invariance across gender was revealed. Females obtained significantly higher scores on social media addiction (SMA) than males. As for concurrent validity, SMA correlated with social media intensity use, anxious attachment, social anxiety, need to belong, self-esteem, and happiness. IRT analysis proved adequate discrimination and difficulty parameters for all items. The highest discrimination was registered by salience criterion and the highest difficulty by conflict, withdrawal, and mood modification criteria. Relapse criterion had the lowest values of both parameters. Network analysis revealed that salience and withdrawal criteria had the highest indicators of centrality and relapse the lowest. Our findings revealed that the most relevant criteria to the diagnosis of SMA in Romanian people are salience, conflict, withdrawal, and mood modification. The robust psychometric properties of the BSMAS-RO provide health professionals a valid instrument for assessing SMA. Programs to prevent SMA must focus on dispositional traits as AATT, social anxiety, respectively unsatisfied need to belong, and promoting the ability to initiate and maintain rewarding social relationships.
\end{abstract}

Keywords Online communication $\cdot$ Maladaptive use of social media $\cdot$ Need to belong $\cdot$ Social anxiety $\cdot$ Happiness

In the present day, communicating through virtual platforms has become inherent to everyday life. Social media (SM) offers people the possibility to communicate with friends,

Elena Stănculescu

elena.stanculescu@fpse.unibuc.ro

1 Faculty of Psychology and Educational Sciences, University of Bucharest, Bucharest, Romania 
meet other people, find romantic partners, play games, shop online, and read the news. In addition to the benefits of instantly connecting with anyone in the world, extending one's friend network, finding entertainment and leisure, reducing anxiety through social interaction, gaining social support (Toma et al., 2020), improving one's motivation to exercise, and finding a sense of belong (Hussain \& Griffiths, 2018), overuse has an impact on mental health (Hou et al., 2019). The popularity of smartphones with Wi-Fi access facilitates the use of SM whenever and wherever. Specialists have emphasized that excessive use of SM can cause addiction (Andreassen et al., 2016). While active SM users have control over their time spent in social virtual world, addicted users do not have control. Griffiths' (2005) recommended criteria for diagnosing behavioral addiction can also be applied to social media addiction (SMA). Griffiths' criteria are as follows: (i) salience (SM dominates one's life); (ii) mood modification (SM is used to improve one's mood); (iii) tolerance (more time spent on SM is required to obtain the previous effects); (iv) withdrawal (impossibility to use social media generates unpleasant feelings); (v) conflict (relationships are negatively affected by one's excessive use of SM); and (vi) relapse (trying to control SM use is conducive to using SM excessively again). Studies have shown significant correlations between problematic or excessive use of SM and psychiatric disorders such as ADHD (Andreassen et al., 2016), depression (Bányai et al., 2017; Donnelly \& Kuss, 2016; Shensa et al., 2017), anxiety (Kircaburun \& Griffiths, 2018; Worsley et al., 2018), social anxiety (Lee-Won et al., 2015), distress (Atroszko et al., 2018), obsessive-compulsive disorder (Andreassen et al., 2016), sleep disorders (Wong et al., 2020), narcissism (Andreassen et al., 2017), dark triad traits (i.e., narcissism, Machiavellianism, and psychopathy, Monacis et al., 2020), and maladaptive emotion regulation strategies (Elhai et al., 2018). A cross-national study developed by Andreassen et al. (2016) found a positive correlation between SMA and user who are young, single, and female. In terms of new types of psychiatric problems, Lin et al. (2019) highlighted that selfitis (the obsessive-compulsive desire to take pictures of oneself and post them on SM) is positively related to SMA. Studies conducted in the context of the COVID-19 pandemic have shown correlations between SMA and fear of COVID-19 (Lin, 2020), and increased distress compared to times before the pandemic (Panno et al., 2020). In addition to these results, associations have been found between excessive use of SM and fear of missing out (Blackwell et al., 2017; Fabris et al., 2020), as well as other types of behavioral addictions, such as internet addiction (Longstreet \& Brooks, 2017), and video game addiction (Andreassen et al., 2016). Researchers have also investigated SMA in a positive psychology framework and highlighted that SMA negatively affects well-being (Duradoni et al., 2020; Worsley et al., 2018), increases online vulnerability, or tendency to experience trauma from cyberbullying (Varchetta et al., 2020). In addition, research has found that excessive immersion in virtual social networks does not compensate for users' dissatisfaction with emotional needs and loneliness (Meshi et al., 2020).

\section{The Current Study}

The aim of this paper was to present the Romanian adaptation of the BSMAS (BSMASRO) in the framework of advanced psychometric analyses as IRT and network approach. The BSMAS has demonstrated good psychometric properties with its original samples (Andreassen et al., 2016), and has been subsequently adapted in various languages as Italian (Monacis et al., 2017), Persian (Lin et al., 2017), Hungarian (Bányai et al., 2017), Chinese (Chen et al., 2020), and American English (Watson et al., 2020). To our knowledge, 
there is no validation study of this scale in any Eastern European country or in Romania to date.

Both classical test theory (CTT), which includes factorial structure, convergent, concurrent, and discriminant validity, and modern approaches such as item response theory (IRT), that is, graded response model analysis (GRM) and network analysis of the BSMAS-RO were applied. Given the one-dimensional structure reported in the original study (Andreassen et al., 2016) and subsequent adaptations, we hypothesized that the Romanian data would fit well with the one-factor structure of the BSMAS. We also hypothesized that a multigroup confirmatory factor analysis (MG-CFA) would cross-validate the single-factor model across gender groups. To verify the BSMAS-RO's concurrent validity, we examined SMA's associations with other research variables. In line with previous findings, we supposed that there would be negative associations between SMA and self-esteem (Andreassen et al., 2016) and happiness (Duradoni et al., 2020; Satici \& Uysal, 2015), respectively positive connections between SMIU (Brailovskaia et al., 2020), AATT (Worsley et al., 2018), social anxiety (Lee-Won et al., 2015), and NTB (Abrams et al., 2011). To investigate the discriminant validity of the BSMAS-RO, we presumed that SMA would represent a distinct psychological construct from AATT and social anxiety. Considering the gender differences in SMA found by Andreassen et al. (2016), we hypothesized that the same pattern would manifest in our Romanian sample. The GRM analysis was performed based on the hypothesis that each item is characterized by good levels of discrimination and difficulty, and would add a significant contribution to the latent variable, i.e., SMA. In addition, we conducted a network analysis to explore the centrality indicators, the strength, closeness, and betweenness index of each node in the estimated network.

\section{Methods}

\section{Participants and Recruitment Procedure}

The sample included 705 participants (39\% males), aged 18-54 years, $M=30.24$, $S D \pm 9.15)$. The convenience sampling strategy was used. We shared an online survey via social networking sites, e-mail campaigns, and WhatsApp to recruit volunteer participants. The questionnaire was designed to be completed in approximately $20 \mathrm{~min}$. It was preset so that each participant could fill in and send only one form. We provided information regarding the objective of the study on the first page, and we received informed consent from all participants. We also allowed participants to withdraw at any stage of the questionnaire without having to explain their decision. Participants were guaranteed that their data would remain confidential and anonymous. All data were collected anonymously, and no intervention was conducted. With regard to attrition, 728 participants were involved in the research at the onset. Some participants only clicked on the questionnaire link or did not complete the items after filling out the sociodemographic variables, which led to an attrition rate of $3.15 \%$. Thus, the final sample consisted of 705 participants who completed the questionnaire.

\section{Ethics}

All procedures followed were in accordance with the ethical standards of the committee on human experimentation. This study adhered to the tenets of the Helsinki Declaration of 
1975 as revised in 2000. Research approval was received from the ethics committee of the University of Bucharest (Reg.No.CEC: 046/10.01.2020).

\section{Measures}

\section{Sociodemographic Variables}

The survey included questions concerning gender, age, and education level to get a profile of the participants' sociodemographic features.

\section{Bergen Social Media Addiction Scale}

The BSMAS (Andreassen et al., 2016) is a six-item scale used to assess SMA (i.e., "Felt an urge to use SM more and more?"). The scale was developed based on Griffiths' (2005) six core characteristics of addiction: salience, mood modification, tolerance, withdrawal, conflict, and relapse. The scale uses a five-point Likert scale, ranging from 1 (very rarely) to 5 (very often). Regarding the threshold between non-disorder and disorder, there are two studies in the literature that have proposed cut-off points for the BSMAS. The score of 19 was established as an empirical cut-off by Bányai et al. (2017). Recently, Luo et al. (2021) proposed a score of 24 as a clinical cut-off point, based on gold standard of clinical diagnosis. In addition, they found that the score of 19 has low accuracy and thus overstates the prevalence of SMA in the sense that those individuals without disorder are wrongly included in the category of addictive users. Therefore, we used in our research the clinical cut-off for BSMAS. In the current study the Cronbach's $\alpha$ was 0.84 (95\% CI [0.82, 0.86]). In the original study (Andreassen et al., 2016), a Cronbach's $\alpha$ of 0.88 was reported. The translation of the BSMAS into the Romanian language was performed based on the forward-backward translation method in accordance with the recommended methodological approach described by Sousa and Rojjanasrirat (2011): (i) the English version of the BSMAS was first translated into Romanian by two independent and qualified translators (one of whom had knowledge of health terminology). The two translated versions of the BSMAS were then compared to check for possible discrepancies in words and meanings and to generate a preliminary translated version. The preliminary translated version was then blind translated back into English by two different qualified translators, and the two backward translations and the original BSMAS were compared to generate the second translated version. No modifications were necessary.

\section{The Social Media Intensity Use Scale}

The social media intensity use scale was adapted from The Facebook intensity scale (Ellison et al., 2007) by replacing "Facebook" with SM. The six items measure the extent to which SM is integrated into one's daily activities. Participants' answers are given using a five-point Likert scale ranging from 1 (strongly disagree) to 5 (strongly agree). Higher scores indicate more SMIU. The Cronbach's $\alpha$ was 0.81 (95\% CI [0.79, 0.82]).

\section{The Interaction Anxiousness Scale)}

The Interaction Anxiousness Scale (IAS) (Leary \& Kowalski, 1993) is a 15-item self-report measure of dispositional social anxiety (i.e., "I seldom feel anxious in social situations"). 
The scale uses a five-point Likert scale, ranging from 1 (not at all characteristic of me) to 5 (extremely characteristic of $m e$ ). Scores for the four positively worded items must be reversed to obtain the total score. Higher scores are indicative of greater social anxiety. The Cronbach's $\alpha$ was 0.87 (95\% CI [0.86, 0.89]).

\section{Revised Adult Attachment Scale}

The Revised Adult Attachment Scale (RAAS) (Collins, 1996) is an 18-item scale that measures adult attachment style that includes three subscales that assess close attachment, anxious attachment, and dependent attachment). The six-item subscale of anxious attachment (i.e., "When I show my feelings for others, I am afraid they will not feel the same about me") assesses the extent to which an individual is worried about being unloved or rejected. The measure uses a five-point Likert scale, ranging from 1 (not at all characteristic of me) to 5 (very characteristic of me). Higher scores on this subscale indicate a greater anxious attachment style. The Cronbach's $\alpha$ obtained for the entire RAAS was 0.76 (95\% CI $[0.73,0.79])$, and the Cronbach's $\alpha$ for the anxious attachment style subscale was 0.74 $(95 \%$ CI $[0.71,0.77])$.

\section{Need to Belong Scale}

The Need to Belong Scale (NBS) (Leary et al., 2013) is a 10-item scale (i.e., "I seldom worry about whether other people care about me") to assess people's desire to form and maintain strong social relationships. The scale uses a five-point Likert scale, ranging from 1 (strongly disagree) to 5 (strongly agree). Higher scores indicate a person's greater need to belong. The Cronbach's $\alpha$ was 0.75 (95\% CI [0.72, 0.77]).

\section{The Rosenberg Self-Esteem Scale}

The Rosenberg Self-Esteem Scale (RSES) (Rosenberg, 1965) is a 10-item self-reported scale that measures self-esteem and includes both positively and negatively worded questions (e.g., "I am able to do things as well as most other people"). The items are answered on a four-point Likert scale, ranging from 1 (never) to 4 (often). Scores for negatively worded items must be reversed to obtain the total score. Higher scores indicate greater selfesteem. The Cronbach's $\alpha$ was 0.81 (95\% CI [0.79, 0.83].

\section{Subjective Happiness Scale}

The Subjective Happiness Scale (SHS) (Lyubomirsky \& Lepper, 1999) is a four-item scale that measures happiness (i.e., "Some people are generally very happy. They enjoy life regardless of what is going on, getting the most out of everything. To what extent does this characterization describe you?"). The items are answered on a seven-point Likert scale, ranging from 1 (not at all) to (a great deal). The Cronbach's $\alpha$ was 0.75 (95\% CI [0.70, $0.79])$.

\section{Data Analysis}

Data analysis was performed using LISREL 9 (2019), Stata 16.1 (2020), ADANCO 2.0.1 (2020), and RStudio qgraph package (2020). The statistical analysis included descriptive 
statistics of the sample characteristics and analysis of the psychometric properties of the BSMAS-RO using CTT, IRT/GRM, and network analysis. First, we measured the internal consistency of the BSMAS-RO based on a congeneric model, McDonald's $\omega$ (McDonald, 1999), and the greatest lower bound ( $g l b$ ) coefficient (Jackson \& Akunwamba, 1977) were computed. Second, we tested the construct validity by means of a confirmatory factor analysis (CFA) using the maximum likelihood estimation method with diagonally weighted least squares (DWLS) based on the polychoric correlations and asymptotic covariance matrix. Various goodness-of-fit indices were computed to determine the acceptability of the model. In addition to the chi-square model, which may lead to model rejection even when the model misspecification is relatively minor (Byrne, 2001), we used the root mean square error of approximation (RMSEA), the standardized root mean square residual (SRMS), the comparative fit index (CFI), and the Tucker-Lewis index (TLI). According to $\mathrm{Hu}$ and Bentler (1999), for CFI and TLI, values greater than 0.90 are acceptable, and values greater than 0.95 are good. The RMSEA and SRMR preferably should be less than or equal to 0.08. Third, we verified the measurement invariance of the BSMAS-RO across gender by a multigroup CFA analysis (MG-CFA). More specifically, configural, metric, and scalar invariance models were investigated, following recommended rules of thumb of $\Delta \mathrm{CFI}<0.01$ and $\Delta$ RMSEA $<0.015$ (Chen, 2007). A Bayesian Independent-Sample Inference procedure was applied to compute Bayesian Factor (BF) of gender differences on SMA. Fourth, we checked the convergent validity by calculating the average variance extracted (AVE) with a cut-off criterion of $>0.50$ (Hair et al., 2009) and by calculating the congeneric or composite reliability (CR) of the scale with a cut-off criterion of $>0.70$ (Chin et al., 2003). Fifth, we tested the concurrent validity based on Pearson correlations between SMA and the ordinal variables self-esteem, happiness, SMIU, AATT, social anxiety, and NTB. Sixth, the discriminant validity was checked using a structural equation modeling that included SMA, social anxiety, and AATT as latent variables. Seventh, we applied IRT, namely GRM analysis, to measure the information given by each item of the scale. Based on the Fisher information provided by each item's characteristics, that is the slope/discrimination $(\alpha)$ and threshold/difficulty $(\beta)$ parameters, we estimated whether the BSMAS-RO lays out more or less psychometric information about latent construct, i.e., SMA. According to Baker (2001), items with a discrimination score greater than 1.7 are considered highly informative. In addition to the $\alpha$ and $\beta$ parameters, graphs of trace lines, curves of each item, and all items together were considered, including boundary characteristic curves (BCCs), the test information function (TIF), and test characteristic curves (TCC). Marginal reliability and expected standard errors (SEE) were computed. Eighth, network analysis of the BSMAS-RO was estimated to explore the visual image of the scale's underlying structure based on item correlations. The indicators of centrality (strength, closeness, and betweenness) of each node were calculated. According to Eskamp et al. (2017), the more central nodes of estimated network have higher centrality values.

\section{Results}

\section{Descriptive Statistics}

The sociodemographic characteristics of our participants are shown in Table 1. Our findings showed that the prevalence of participants whose overall score on SMA exceeds the 
Table 1 Sociodemographic variables-distribution depending on the clinical cut-off for SMA

\begin{tabular}{lllll}
\hline Gender & & $\begin{array}{l}\text { Number of participants with } \\
\text { SMA global score below the } \\
\text { clinical cut-off }\end{array}$ & $\begin{array}{l}\text { Number of participants with } \\
\text { SMA global score above the } \\
\text { clinical cut-off }\end{array}$ & $\begin{array}{l}\text { Total number } \\
\text { of participants }\end{array}$ \\
\hline \multirow{4}{*}{ Age } & Male & 263 & 11 & 274 \\
& Female & 412 & 19 & 431 \\
& $18-25$ & 218 & 28 & 246 \\
& $26-35$ & 158 & 2 & 160 \\
& $36-45$ & 191 & 0 & 191 \\
\multirow{5}{*}{ Education } & $46-54$ & 108 & 0 & 108 \\
& High-school & 287 & 16 & 303 \\
& Bachelor & 224 & 12 & 236 \\
& Master & 164 & 2 & 166 \\
\hline
\end{tabular}

clinical cut-off is $4.25 \%$. This value is similar to that obtained by Luo et al. (2021), who reported that $3.25 \%$ of the participants were addicted users.

The mean, $S D$, skewness, and kurtosis of research variables are provided in Table 2, and those of each item of the BSMAS-RO in Table 3. In the case of the global scores of research variables, univariate normality was obtained (as shown in Table 2), except SMA who's score was positively skewed. Although some items of the BSMAS-RO were positively skewed, no substantial departures from univariate normality were found.

In addition, significant Mardia's skewness [mSkewness $=11.41 ; \chi^{2}(56)=676.93$, $p<0.001]$ and significant Mardia's kurtosis $\left[\right.$ KKurtosis $\left.=74.77 ; \chi^{2}(1)=657.31, p<0.001\right]$ proved the multivariate non-normality.

\section{BSMAS-RO Validity Using CTT (Classical Test Theory)}

\section{Internal Consistency}

The McDonald's $\omega=0.84$; (95\% CI $[0.82,0.86])$ and $g l b=0.86$; $(95 \%$ CI $[0.84,0.89])$ indicated good internal consistency of the BSMAS-RO. In addition, internal consistency

Table 2 Descriptive statistics of the research variables (mean, SD, skewness, kurtosis)

\begin{tabular}{lrrll}
\hline Variable & Mean & $S D$ & $\begin{array}{l}\text { Skewness } \\
\text { (Std error of skewness) }\end{array}$ & $\begin{array}{l}\text { Kurtosis } \\
\text { (Std error of kurtosis) }\end{array}$ \\
\hline SMA & 11.17 & 5.47 & $1.198(.092)$ & $0.909(.184)$ \\
SMIU & 13.89 & 4.71 & $0.137(.092)$ & $-0.600(.184)$ \\
Social anxiety & 43.85 & 11.68 & $-0.106(.092)$ & $-0.514(.184)$ \\
AATT & 8.93 & 3.77 & $0.558(.092)$ & $-0.296(.184)$ \\
NTB & 31.31 & 7.27 & $-0.222(.092)$ & $-0.183(.184)$ \\
Self-esteem & 38.57 & 6.92 & $-0.411(.092)$ & $0.149(.184)$ \\
Happiness & 13.62 & 3.14 & $-0.081(.092)$ & $-0.464(.184)$ \\
\hline
\end{tabular}

Abbreviations: $S M A$ social media addiction, SMIU social media intensity use, AATT anxious attachment, $N T B$ need to belong 
Table 3 Descriptive statistics—reliability, mean, $S D$, skewness, and kurtosis of all items of the BSMAS$\mathrm{RO}$

\begin{tabular}{|c|c|c|c|c|c|c|c|}
\hline \multirow[t]{2}{*}{ Item } & \multicolumn{2}{|l|}{ If item dropped } & \multirow{2}{*}{$\begin{array}{l}\text { Corrected item- } \\
\text { total correlation }\end{array}$} & \multirow[t]{2}{*}{ Mean } & \multirow[t]{2}{*}{$S D$} & \multirow{2}{*}{$\begin{array}{l}\text { Skewness } \\
\text { (Std. error of } \\
\text { skewness) }\end{array}$} & \multirow{2}{*}{$\begin{array}{l}\text { Kurtosis } \\
\text { (Std. error of } \\
\text { kurtosis) }\end{array}$} \\
\hline & McDonald's $\omega$ & Cronbach's $\alpha$ & & & & & \\
\hline SMA1 & 0.807 & 0.806 & 0.690 & 1.679 & 1.106 & $1.70(.092)$ & $2.06(.184)$ \\
\hline SMA2 & 0.811 & 0.811 & 0.657 & 2.109 & 1.285 & $0.85(.092)$ & $-0.49(.184)$ \\
\hline SMA3 & 0.817 & 0.816 & 0.629 & 1.930 & 1.227 & $1.10(.092)$ & $0.02(.184)$ \\
\hline SMA4 & 0.850 & 0.849 & 0.490 & 2.089 & 1.407 & $0.96(.092)$ & $-0.49(.184)$ \\
\hline SMA5 & 0.810 & 0.808 & 0.678 & 1.695 & 1.134 & $1.58(.092)$ & $1.42(.184)$ \\
\hline SMA6 & 0.817 & 0.816 & 0.631 & 1.665 & 1.131 & $1.69(.092)$ & $1.82(.184)$ \\
\hline
\end{tabular}

could not be improved by removing any of the items (see Table 3). The corrected-itemtotal correlations were all positive and between 0.49 and 0.69 (see Table 3). As well, all the inter-item correlation coefficients were higher than 0.30 (as recommended by Cohen, 1992). These results indicate that the items surveyed in the BSMAS-RO effectively reflect the latent construct, i.e., SMA.

\section{Confirmatory Factor Analysis}

The CFA revealed that all of the estimated factor loadings were statistically significant at $p<0.001$. As displayed in Table 4, standardized factor loadings for all items were statistically significant and well above the cut-off criterion $>0.50$ (Pituch \& Stevens, 2016). The factor loadings ranged between 0.75 and 0.93 .

In terms of model fitting, a chi-square test was significant, $\chi^{2}(9)=38.074(p<0.001)$, which could indicate possible discrepancies or misfitting, but it is accepted in the literature (Pituch \& Stevens, 2016) that a chi-square test is impacted by a large sample size. Because CFA is a large sample technique, it is not uncommon to obtain a significant chi-square test. The results proved an optimal model fit for the BSMAS-RO, with GFI $=0.992$, CFI $=0.981$, $\mathrm{IFI}=0.981$, TLI $=0.969, \mathrm{RMSEA}=0.068 ; 90 \% \mathrm{CI},[0.046,0.091], \mathrm{SRMR}=0.024$, and $\mathrm{CD}=0.86$. These findings certify that the single-factor structure of the BSMAS-RO fit the data very well.

Table 4 The results of the CFA analysis of the BSMAS-RO- $\lambda, \xi, Z, p$, and $95 \%$ confidence interval

\begin{tabular}{|c|c|c|c|c|c|c|c|}
\hline \multirow[t]{2}{*}{$\begin{array}{l}\text { Item } \\
\text { (criterion) }\end{array}$} & \multirow[t]{2}{*}{$\lambda$} & \multirow[t]{2}{*}{$\xi$} & \multirow[t]{2}{*}{$Z$} & \multirow[t]{2}{*}{$p$} & \multicolumn{2}{|c|}{$\begin{array}{l}95 \% \text { confidence } \\
\text { interval }\end{array}$} & \multirow{2}{*}{$\begin{array}{l}\text { Item } \\
\text { excluded or } \\
\text { included }\end{array}$} \\
\hline & & & & & Lower & Upper & \\
\hline 1. Salience & 0.86 & 0.053 & 16.16 & .001 & 0.75 & 0.96 & Retained \\
\hline 2. Tolerance & 0.94 & 0.047 & 20.03 & .001 & 0.85 & 1.04 & Retained \\
\hline 3. Mood modification & 0.85 & 0.040 & 17.16 & .001 & 0.76 & 0.95 & Retained \\
\hline 4. Relapse & 0.74 & 0.058 & 12.74 & .001 & 0.63 & 0.85 & Retained \\
\hline 5. Withdrawal & 0.82 & 0.049 & 16.68 & .001 & 0.73 & 0.92 & Retained \\
\hline 6. Conflict & 0.79 & 0.053 & 15.02 & .001 & 0.68 & 0.89 & Retained \\
\hline
\end{tabular}


The findings obtained in the MG-CFA across gender proved that the BSMAS-RO measures the same construct in both gender groups. The configural (same structure in both groups), metric (equal item loadings), scalar (equal item intercepts), and strict (equal item residuals) invariance models showed good fit indices, as set out in Table 5. In addition, the changes in model fit indices ( $\triangle \mathrm{CFI}, \triangle \mathrm{RMSEA}$ ) between (i) configural and metric, (ii) metric and scalar, and (iii) scalar and strict were lower than the recommended cut-off (Chen, 2007). In terms of gender differences, Bayesian Inference analysis revealed a moderate difference: $\mathrm{BF}=0.21, t(703)=2.88, p=0.004$. More specifically, females had significant higher SMA scores $(M=11.43, S D=5.57)$ than males $(M=9.79, S D=4.55)$.

\section{Convergent Validity}

By using $\lambda$ and $\varepsilon$ computed in CFA, we calculated AVE and CR. The results obtained $(\mathrm{AVE}=0.69$ and $\mathrm{CR}=0.93)$ certified that both $\mathrm{AVE}$ and $\mathrm{CR}$ were well above the recommended cut-off (AVE>0.50), according to Hair et al. (2009), respectively CR $>0.70$, as suggested by Chin et al. (2003).

\section{Concurrent Validity}

Results showed that the BSMAS-RO's total score negatively correlated with self-esteem, $r(703)=-0.19, p<0.01$, and happiness, $r(703)=-0.11, p<0.01$. Additionally, positive relations were found with SMIU, $r(703)=0.54, p<0.01$, AATT, $r(703)=0.41, p<0.01$, social anxiety, $r(703)=0.21, p<0.01$, and NTB, $r(703)=0.23, p<0.01$.

\section{Discriminant Validity}

The HTMT criteria obtained in the ratio of correlations analysis in variance-based SEM proved that the BSMAS-RO assesses psychological phenomena that the other two latent variables (social anxiety and AATT) do not capture. The results certified that SMA is a distinct concept from social anxiety $(\mathrm{HTMT}=0.24)$, respectively different from AATT $($ HTMT $=0.38)$, being satisfied the cut-off $($ HTMT $<0.85)$ as recommended by Henseler (2020).

Table 5 Measurement invariance for the BSMAS-RO

\begin{tabular}{|c|c|c|c|c|c|c|c|c|}
\hline $\begin{array}{l}\text { Model } \\
\text { Invariance }\end{array}$ & $\chi^{2}$ & df & CFI & $\begin{array}{l}\text { RMSEA } \\
(95 \% \mathrm{CI})\end{array}$ & $\Delta \chi^{2}(\Delta \mathrm{df})$ & $\Delta \mathrm{CFI}$ & $\Delta$ RMSEA & Decision \\
\hline $\begin{array}{l}\text { Model } 1 \\
\text { Configural }\end{array}$ & 51.72 & 18 & .978 & $\begin{array}{l}.073 \\
{[.050, .097]}\end{array}$ & - & - & - & Accept \\
\hline $\begin{array}{l}\text { Model } 2 \\
\text { Metric }\end{array}$ & 55.38 & 23 & .979 & $\begin{array}{l}.063 \\
{[.042, .085]}\end{array}$ & $3.66(5)$ & -.001 & .010 & Accept \\
\hline $\begin{array}{l}\text { Model } 3 \\
\text { Scalar }\end{array}$ & 68.59 & 28 & .973 & $\begin{array}{l}.064 \\
{[.045, .084]}\end{array}$ & $13.21(5)$ & .006 & -.001 & Accept \\
\hline $\begin{array}{l}\text { Model } 4 \\
\text { Strict }\end{array}$ & 89.79 & 34 & .963 & $\begin{array}{l}.068 \\
{[.051, .086]}\end{array}$ & $21.20(6)$ & .010 & -.004 & Accept \\
\hline
\end{tabular}




\section{BSMAS-RO Validity Using IRT/GRM}

\section{Item Parameter Estimates for the BSMAS-RO}

Discrimination Parameters As shown in Table 6, various slopes or discrimination parameters $(\alpha)$ were registered. They ranged between 1.43 and 3.22. By convention, items with discrimination score of higher than 1.70 are considered highly informative, cut-off level being 0.60 (Backer, 2001), which means that they could distinguish better between low and high levels of the latent trait, that is SMA. Thus, our findings proved that all items of the BSMAS-RO were not only contributory, but also had good capacity when discriminating the underlying SMA dimension.

In terms of increasing discrimination values, the relapse criterion (item 4 ) had a lower value than all others criteria. Its value (1.43) was well above the cut-off $(>0.60)$, which indicates a moderate ability to discriminate between low and high levels of the latent construct. The highest discrimination value $(>3)$ was obtained for the salience criterion (item 1). The remaining items also had high values, ranging from 2.65 to 2.25. Although item 4 provided less information for the scale than other items, we determined that it should not be removed because it was well above the recommended cut-off level. Therefore, the underlying relapse criterion had a moderate relationship with the latent construct, and all the other items a strong connection with SMA.

Difficulty Parameters The results demonstrated some degree of variability for the difficulty parameter $(\beta)$ values (see Table 6 and Fig. 1). For example, in the case of the salience criterion, for a $\theta$ score $<+1.54$ there was $50 \%$ chance of responding "very rarely," "rarely," or "sometimes" and for a $\theta$ score $>+1.54$ there was $50 \%$ probability of answering "often" or "very often." Except for one threshold of one single item (i.e., $\beta_{1}$ for the item 2), all other items had positive threshold values or difficulties. The negative difficulty parameter is indicative that item 2 is relatively easy to be endorsed.

As indicated in Table 6 , the fourth threshold $\left(\beta_{4}\right)$ for all of the items was located between 1.80 and 2.12 SD from the mean for BSMAS-RO. Additionally, $\beta_{4}$ was higher for items 6 (conflict), 5 (withdrawal), and 3 (mood modification) than items 2 (tolerance), 1 (salience), and 4 (relapse). This result means that choosing "very often" for items 6,5 , and 3 indicates higher levels of SMA than when selecting the same response category for items 2,1 , and 4 . The difference between the highest difficulty parameter (item 6) and the lowest

Table 6 Item parameters-slopes and thresholds for the BSMAS-RO items

\begin{tabular}{|c|c|c|c|c|c|c|c|c|c|c|c|}
\hline \multirow[t]{2}{*}{ Item (criterion) } & \multirow[t]{2}{*}{$\alpha$} & \multirow[t]{2}{*}{ Std. error } & \multirow[t]{2}{*}{$Z$} & \multirow[t]{2}{*}{$p$} & \multicolumn{3}{|c|}{$[95 \% \mathrm{CI}]$} & \multirow[t]{2}{*}{$\mathrm{B}_{1}$} & \multirow[t]{2}{*}{$\mathrm{B}_{2}$} & \multirow[t]{2}{*}{$\mathrm{B}_{3}$} & \multirow[t]{2}{*}{$\mathrm{B}_{4}$} \\
\hline & & & & & Lowe & & Upper & & & & \\
\hline 1 Salience & 3.22 & 0.29 & 11.05 & .001 & 2.69 & 3.79 & & 0.42 & 0.98 & 1.51 & 1.84 \\
\hline 2 Tolerance & 2.62 & 0.20 & 12.75 & .001 & 2.22 & 3.03 & & -0.07 & 0.59 & 1.08 & 1.80 \\
\hline 3 Mood modification & 2.25 & 0.18 & 12.41 & .001 & 1.89 & 2.61 & & 0.14 & 0.72 & 1.31 & 2.05 \\
\hline 4 Relapse & 1.43 & 0.12 & 11.28 & .001 & 1.18 & 1.68 & & 0.17 & 0.74 & 1.34 & 1.93 \\
\hline 5 Withdrawal & 2.65 & 0.22 & 11.65 & .001 & 2.20 & 3.10 & & 0.47 & 0.99 & 1.48 & 2.08 \\
\hline 6 Conflict & 2.29 & 0,19 & 11.60 & .001 & 1.90 & 2.67 & & 0.54 & 1.13 & 1.57 & 2.12 \\
\hline
\end{tabular}



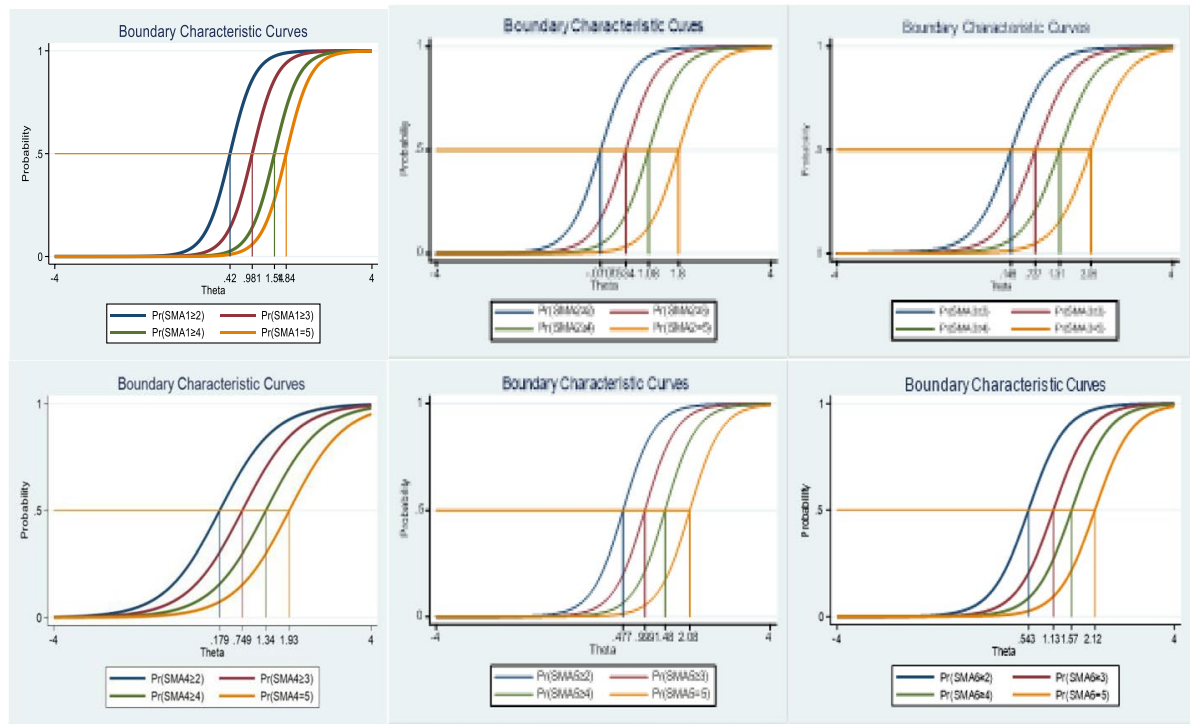

Fig. 1 Boundary characteristic curves (BCCs) for each item of the BSMAS-RO

difficulty parameter (item 4) indicates that the response to item 6 is more likely due to the individual's level of SMA than the response to item 4. In other words, the conflict criterion (item 6) required relatively higher levels of SMA to be endorsed because it had the highest difficulty value. In contrast, the relapse criterion (item 4) was endorsed at relatively lower levels of SMA. Therefore, we can consider items 6 (conflict criterion: "Used SM so much that it has had a negative impact on your job/studies"), 5 (withdrawal criterion: "Become restless or troubled if you have been prohibited from using SM"), and 3 (mood modification criterion: "Used SM in order to forget about personal problems?") as the most difficult to be endorsed.

\section{Item Information Function}

As depicted in Fig. 2, the IIFs were unimodal, except the first one, which was bimodal. This fact is not unusual because each category of responses (from 1 to 5) contributes its own information, which may peak over a different trait range. All criteria, except the relapse criterion (item 4), provided a reasonable amount of information, peaking at around +1.7 SD to +3.2 SD from the mean. The high amount of information, peaking at around +3.2SD, respectively $+3.1 S D$, and therefore high reliability was provided by the bimodal salience criterion (item 1), followed by the tolerance criterion (item 2, which peaked around +2.2 SD) and the withdrawal criterion (item 5, which peaked around +2.2 SD). Moderately high information was provided by the mood modification criterion (item 3, which peaked around +1.7 SD) and the conflict criterion (item 6 , which peaked around $+1.7 S D$ ). As mentioned above, the least reliable item was the relapse criterion (item 4 , which peaked around + 0.6 SD). 

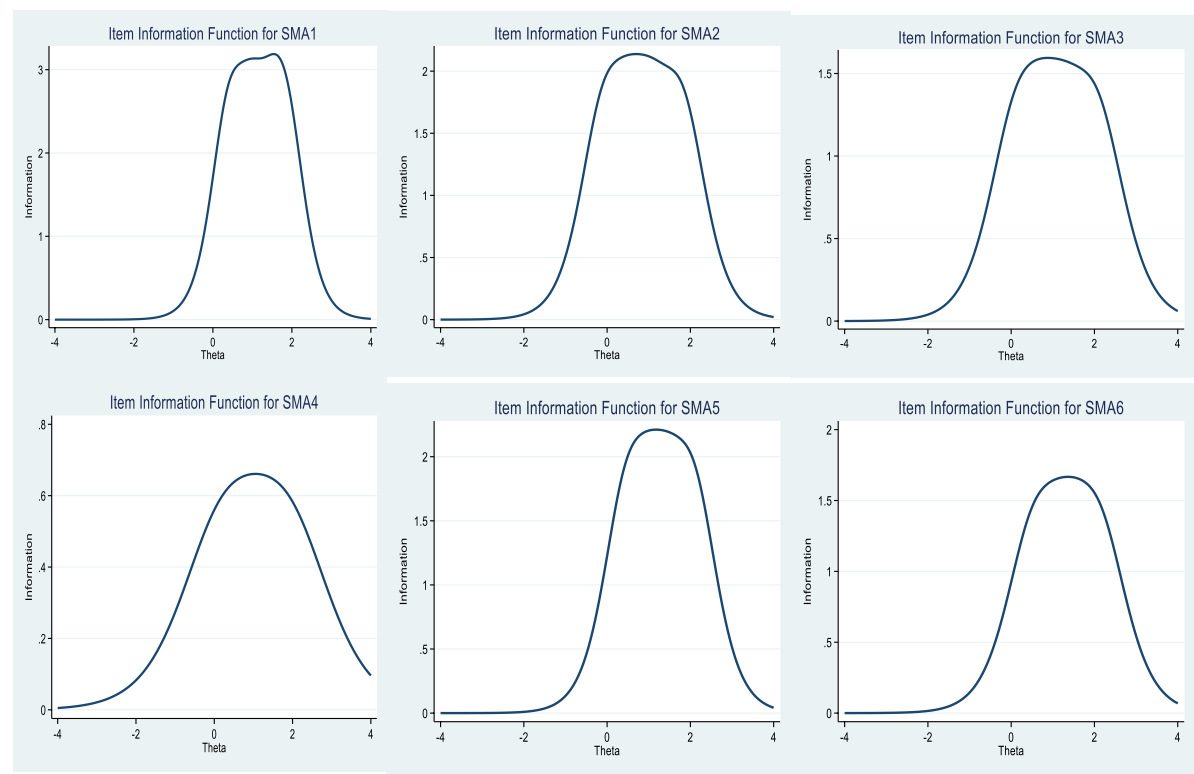

Fig. 2 Item information function for the BSMAS-RO

\section{Test Information Function and Test Characteristic Curve for the BSMAS-RO}

The TIF shows the degree of precision of difficult values of $\theta$ or how much information items contribute and what portion of the scale includes score range. As shown in Fig. 3, for the BSMAS-RO, the TIF provided relatively uniform information about individuals between $\theta[-1 ; 3]$ with a decline beyond those points in either direction. There was reasonable amount of scale information at around -0.5 and +2.5 SD from the mean, peaking at around $+1 \mathrm{SD}$ from the mean. The maximum amount of information (precision) was
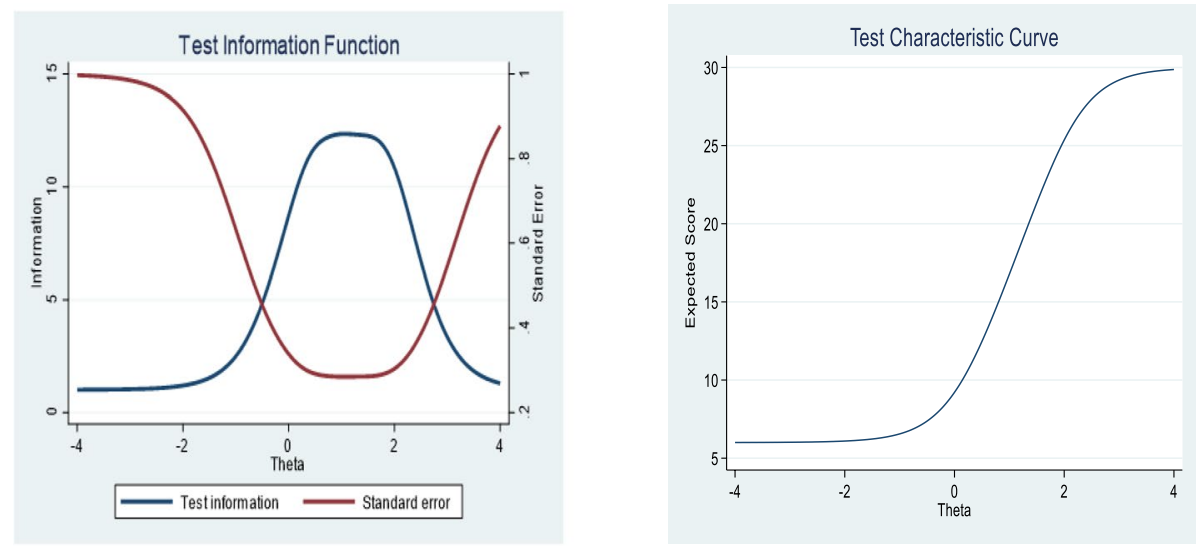

Fig. 3 Test information function (blue line) and standard errors (red line) and test characteristic curve for the BSMAS-RO 
approximately 12.6 around the latent construct estimates. For a broad range, [0.5; 2], marginal reliability was 0.92 and expected standard error (SEE) was 0.28 , which is slightly under one third of a standard deviation. Outside of this range, more precisely, $[-0.5 ; 0.5]$ and $[2 ; 2.5]$, marginal reliability slowly decreases $(0.80)$, and SEE increases $(0.44)$, which is below one half of a standard deviation anyway. Thus, the TIF proved the BSMAS-RO functions well as a whole, provides as a precise estimation of scores for a broad range of the continuum, and has very good marginal reliability and low SEE.

The graph of TCC (as shown in Fig. 3) maps latent variable $\theta$ back to the expected test scores. The TCC shows that SMA increases steeply and monotonically steeply, as the criteria were endorsed from 6 to 30. Thus, the steep curve highlights that the BSMAS-RO is a robust psychometric measure for various levels of SMA. In addition, the TCC emphasizes that the average of the expected scores was around 10 . With regard to the $95 \%$ confidence bound of the $\theta$ score, we expected roughly $95 \%$ of the scores to fall between 6 and 24 .

\section{Network analysis of the BSMAS-RO}

As shown in the estimated network (see Fig. 4), one single cluster was obtained, and all nodes were positively associated with each other. Item 1 (salience) and 5 (withdrawal) had strong connections with three other items in the network, item 2 (tolerance) and 6 (conflict) had strong connections with two other items, and item 3 (mood modification) and 4 (relapse) had only one strong connection with another item in the network.

In terms of the first indicator of centrality, i.e., the strength nodes, items 1 and 5 have the strongest direct connection with the network, and items 3 and 4 have the weakest direct connection. Regarding the second indicator of centrality, the closeness index, items 1 and 5 have the highest indirect connection (i.e., the sum of all shortest paths between the node and all others nodes in the network) and item 4 has the lowest. The results of the third

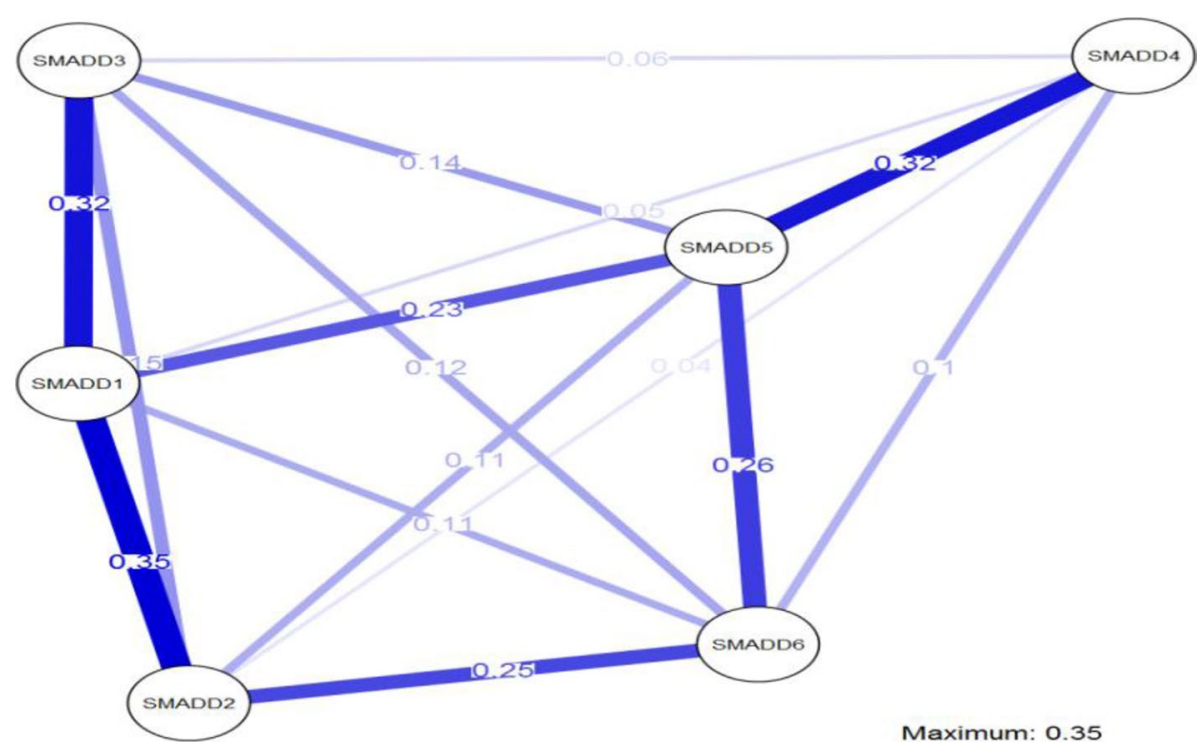

Fig. 4 Estimated correlation network of the BSMAS-RO, association values-the thickness of the edge indicates the strength of the association between the nodes 
centrality indicator, the betweenness index, emphasize that items 1 and 5 have the highest scores because they often lay on the shortest path connecting two other nodes in the network. Items 2, 3, 4, and 6 were the least common on such paths. Overall, these findings indicate that items 1 (salience) and 5 (withdrawal) are more central in the estimated network, and item 4 (relapse) has the lowest centrality value.

\section{Discussion}

The results of this study demonstrated that the BSMAS-RO is a psychometrically robust measure of SMA. As in Andreassen et al.'s (2016) original study, the BSMAS-RO has a unidimensional structure with high internal consistency proved by McDonald's $\omega, g l b, C R$, and marginal reliability. The CFA proved very good fit of the specified model to the data, as all items significantly loaded on the latent construct. In terms of the MG-CFA, measurement invariance across gender was supported for the BSMA-RO, which highlighted that males and females had similar interpretations of the items' content. These findings align with previous studies (Andreassen et al., 2016; Bányai et al., 2016; Chen et al., 2020; Monacis et al., 2017). The hypothesis regarding the concurrent validity of the BSMASRO was validated because we found negative associations between SMA, on the one hand, and self-esteem and happiness, on the other hand, respectively positive correlations with SMIU, social anxiety, and AATT. Convergent validity was confirmed by AVE and CR, whose values were well above the recommended cut-off criteria. The results of the heterotrait-monotrait analysis indicated the discriminant validity of the BSMAS-RO, proving that the assessed latent construct, i.e., SMA, is different from social anxiety and AATT. Considering the validation studies carried out previously, Monacis et al.'s research (2017) seems comparable to our study because it was performed in Italy, which has some cultural similarities to Romania (both being Latin countries). We noticed that in the CFA, the relapse criterion (item 4 ) had the lowest $\lambda$ coefficient. The same pattern was obtained in the aforementioned Italian study.

The GRM analysis revealed that the BSMAS-RO is a psychometrically robust instrument, taking into account that the slopes and thresholds obtained were highly informative of individuals in terms of SMA. The TIF provided evidence that the BSMAS-RO functioned well as a whole, emphasized a precise estimation of scores for a broad range of the continuum, and had very good marginal reliability and low SEE. In addition, GRM analysis confirmed that the relapse criterion was moderately informative for the latent construct, and all other criteria (salience, conflict, withdrawal, mood modification, and tolerance) were highly informative - the highest value being obtained by the salience criterion. Additionally, the conflict, withdrawal, and mood modification criteria were the most difficult to be endorsed. Because conflict, withdrawal, and mood modification criteria are considered core aspects in the identification of behavioral addictions (Kuss \& Griffiths, 2017), we can emphasize that the BSMAS-RO has the same overarching structure specific to addictive use behavior. The network analysis revealed the existence of a single cluster in line with the structure highlighted in the CFA. It was also observed that the salience and withdrawal criteria had the highest indicators of centrality: strength, closeness, and betweenness. The relapse criterion recorded the lowest values for all three indicators. Therefore, the results obtained in the network analysis parallel those found in the GRM analysis. More precisely, it is noticed that those items with the highest scores on indicators of centrality in network analysis also proved to be highly informative for the latent construct, as emphasized in 
GRM analysis. The lowest centrality value was obtained by the relapse criterion, which proved to be the least informative item and to have the least discrimination value in the GRM analysis.

The strengths of this study encompass various aspects. First, this is the first validation study of the BSMAS conducted in an Eastern European country, more precisely in Romanian culture. Previous validation studies of adapted version of BSMAS were conducted in Western (Monacis et al., 2017), American (Watson et al., 2020), and Asian cultures (Chen et al., 2020; Lin et al., 2017; Luo et al., 2021). Second, this is the first study based on the modern approach of GRM analysis in the framework of IRT. Only one previous study (Lin et al., 2017) was developed based on the Rasch model, also from the perspective of IRT. We chose the GRM because it is considered to be best suited for the analysis of a fivepoint Likert scale, as the Rasch model requires dichotomous responses. One of the most important benefits of this modern approach is that the latent variable's level is estimated based on (i) raw scores, (ii) score patterns, and (iii) item properties, while in the CTT, the latent variable's level is estimated based only on the raw scores. Third, reliability was calculated using both classical and modern perspectives. More precisely, in terms of CTT, the McDonald's $\omega$ coefficient and $g l b$ were computed. In terms of modern approach, the graphs of IIF and TIF, respectively marginally reliability were calculated. While the CTT's reliability shows only the average of all items, IRT has the advantage of providing through the IIF graph a bottom-up perspective of reliability. More precisely, it registers different variations depending on the pattern of each item. Thus, this study offers a more extensive approach towards psychometric qualities of the BSMAS. Fourth, the validation based on the CTT analysis included multiple types of validity: (i) construct, (ii) convergent, (iii) concurrent, and (iv) discriminant. In addition, discriminant validity analysis was conducted using the heterotrait-monotrait model. Sixth, this study was the first to use the exploratory method of network analysis of the BSMAS. Through GRM and network analysis, the BSMAS-RO's most difficult, discriminant, respectively central items were identified. Thus, we found the items that provide the highest information for the latent construct, i.e., SMA, namely salience, conflict, and withdrawal. The relapse criterion was less informative (moderate level) and had the least indicator of centrality. The weaker relationship between the item underlying relapse criterion and the latent variable, i.e., SMA, compared to all the other items suggests that the observed variability of this criterion is caused more by factors other than SMA. Fifth, our findings are contributing to the extension of the existing body of research on dispositional traits as antecedents of SMA. We highlighted that SMA is no longer a rational choice determined but actual utility, but is explained by emotional insecurities because of social anxiety and AATT. In addition, we provided empirical support for the negative predictive role of SMA on the affective dimension of subjective well-being, i.e., happiness. These results add a complementary view to previous findings (Toma et al., 2020) which highlighted the relationship between SM use and psychological well-being.

Beyond these strengths, our research has some limitations. First, the cross-sectional design precluded the analysis of causal links between the investigated variables. Moreover, the data obtained using self-reported methods can be influenced by desirability and recall biases, which is why future longitudinal studies are needed. Second, convenience sampling does not enable the generalization of our results. Third, no data were collected using diagnostic measures (see Structured Clinical Interview for DSM-5), and it was not possible to measure the sensitivity of the BSMAS for detecting psychiatric-related symptoms.

All in all, our findings based on advanced psychometric testing (e.g. IRT and network analysis) highlighted that the BSMAS-RO is an easy-to-use, reliable, and valid instrument to assess the risk of SMA in Romanian population. Furthermore, salience, conflict, 
withdrawal, and mood modification are the most relevant criteria to the diagnosis of SMA in Romanian people. Thus, Romanian researchers can use this tool to assess people's risk of SMA and to investigate SMA's predictors, moderators, and consequences on psychological health. Programs to prevent SMA must focus on dispositional traits as AATT, social anxiety, and unsatisfied NTB, promoting the ability to initiate and maintain rewarding social relationships.

Funding This research did not receive any specific grant from funding agencies in the public, commercial, or not-for-profit sectors.

\section{Declarations}

Ethics approval The research was approved by the Research Ethics Committee of the University of Bucharest (Reg.No.CEC: 046/10.01.2020).

Conflict of interest None.

\section{References}

Abrams, D., Weick, M., Thomas, D., Colbe, H., \& Franklin, K. M. (2011). On-line ostracism affects children differently from adolescents and adults. British Journal of Developmental Psychology, 29, 110-123.

ADANCO 2.2 (2020). Composite modeling. Advances analysis of composite. Composite Modeling GmbH \&Co.

Andreassen, C. S., Billieux, J., Griffiths, M. D., Kuss, D. J., Demetrovics, Z., Mazzoni, E., \& Pallesen, S. (2016). The relationship between addictive use of social media and video games and symptoms of psychiatric disorder: A large-scale cross-sectional study. Psychology of Addictive Behaviors, 30, 252-262. https://doi.org/10.1037/adb0000160

Andreassen, C. S., Pallesen, S., \& Griffiths, M. D. (2017). The relationship between addictive use of social media, narcissism, and self-esteem: Findings from a large national survey. Addictive Behaviors, 64, 287-293.

Atroszko, P. A., Balcerowska, J. M., Bereznowski, P., Biernatowska, A., Pallesen, S., \& Andreassen, C. S. (2018). Facebook addiction among Polish undergraduate students: Validity of measurement and relationship with personality and well-being. Computers in Human Behavior, 85, 329-338. https://doi.org/ 10.1016/j.chb.2018.04.001

Baker, F. B. (2001). Item characteristic curve models. In C. Boston \& L. Rudner (Eds.), The basics of item response theory (pp. 21-34). ERIC Clearinghouse on Assessment and Evaluation.

Bányai, F., Zsila, Á., Király, O., Maraz, A., Elekes, Z., Griffiths, M. D., \& Demetrovics, Z. (2017). Problematic social media use: Results from a large-scale nationally representative adolescent sample. PLoS ONE, 12(1), e0169839. https://doi.org/10.1371/journal.pone.0169839

Blackwell, D., Leamon, C., Tramposch, R., Osborne, C., \& Liss, M. (2017). Extraversion, neuroticism, attachment style and fear of missing out as predictors of social media use and addiction. Personality and Individual Differences, 116, 69-72.

Byrne, B. M. (2001). Structural equation modeling with AMOS. Lawrence Erlbaum Associates.

Chen, F. F. (2007). Sensitivity of goodness of fit indexes to lack of measurement invariance. Structural Equation Modeling, 14, 464-504. https://doi.org/10.1080/10705510701301834

Chen, I. H., Strong, C., Lin, Y. C., Tsai, M. C., Leung, H., Lin, C. Y., Pakpour, A. H., \& Grifiths, M. D. (2020). Time invariance of three ultra-brief internet-related instruments: Smartphone ApplicationBased Addiction Scale (SABAS), Bergen social media addiction scale (BSMAS), and the nine-item internet gaming disorder scale-short form (IGDS-SF9) (Study part B). Addictive Behaviors, 101,. https://doi.org/10.1016/j.addbeh.2019.04.018

Chin, W., Marcolin, B., \& Newsted, P. (2003). A partial least squares latent variable modeling approach for measuring interaction effects: Results from a Monte Carlo simulation study and an electronic-mail emotion/adoption study. Information Systems Research, 14(2), 189-217.

Cohen, J. (1992). Statistical power analysis. Current Directions in Psychological Science, 1(3), 98-101. 
Collins, N. L. (1996). Working models of attachment: Implications for explanation, emotion, and behaviour. Journal of Personality and Social Psychology, 71, 810-832.

Donnelly, E., \& Kuss, D. (2016). Depression among users of social networking sites (SNSs): The role of SNS addiction and increased usage. Journal of Addiction and Preventive Medicine, 2(1). https:// doi.org/10.19104/japm.2016.107

Duradoni, M., Innocenti, F., \& Guazzini, A. (2020). Well-being and social media: A systematic review of Bergen Addiction Scales. Future Internet, 12(24). http://doi.org/https://doi.org/10.3390/fi120 2002

Elhai, J. D., Tiamiyu, M. F., Weeks, J. W., Levine, J. C., Picard, K. J., \& Hall, B. J. (2018). Depression and emotion regulation predict objective smartphone use measured over one week. Personality and Individual Differences, 133, 21-28. https://doi.org/10.1016/J.PAID.2017.04.051

Ellison, N. B., Steinfield, C., \& Lampe, C. (2007). The benefits of Facebook "friends:" Social capital and college students' use of online social network sites. Journal of Computer Mediated Communication, 12, 1143-1168.

Fabris, M. A., Marengo, D., Longobardi, C., \& Settanni, M. (2020). Investigating the links between fear of missing out, social media addiction, and emotional symptoms in adolescence: The role of stress associated with neglect and negative reactions on social media. Addictive Behaviors, 106,. https:// doi.org/10.1016/j.addbeh.2020.106364

Griffiths, M. D. (2005). A component model of addiction within a biopsychosocial framework. Journal of Substance Use, 10, 191-197.

Hair, J. F., Black, W. C., Babin, B. J., \& Anderson, R. E. (2009). Multivariate data analysis. PrenticeHall Inc.

Henseler, J. (2020). Composite-based structural equation modeling: Analyzing latent and emergent variables. Guilford Press.

Hou, Y., Xiong, D., Jiang, T., Song, L., \& Wang, Q. (2019). Social media addiction: Its impact, mediation, and intervention. Cyberpsychology: Journal of Psychosocial Research on Cyberspace, 13(1). https://doi.org/10.5817/CP2019-1-4

Hu, L., \& Bentler, P. M. (1999). Cut-off criteria for fit indexes in covariance structure analysis: Conventional criteria versus new alternatives. Structural Equation Modelling, 6, 1-55.

Hussain, Z., \& Griffiths, M. G. (2018). Problematic social networking site use and comorbid psychiatric disorders: A systematic review of recent large-scale studies. Frontiers in Psychiatry, 9, 686. https:// doi.org/10.3389/fpsyt.2018.00686

Jackson, P., \& Agunwamba, C. (1977). Lower bounds for the reliability of the total score on a test composed of non-homogeneous items: I: Algebraic lower bounds. Psychometrika, 42(4), 567-578. https://doi.org/10.1007/BF02295979

Kircaburun, K., \& Griffiths, M. D. (2018). Instagram addiction and the Big Five of personality: The mediating role of self-liking. Journal of Behavioral Addiction, 7, 158-170.

Kuss, D. J., \& Griffiths, M. D. (2017). Social networking sites and addiction: ten lessons learned. International Journal of Environmental Research and Public Health, 14(311). https://doi.org/10.3390/ ijerph14030311

Leary, M. R., Kelly, K. M., Cottrell, C. A., \& Schreindorfer, L. S. (2013). Construct validity of the need to belong scale: Mapping the nomological network. Journal of Personality Assessment, 95(6), 610-624. https://doi.org/10.1080/00223891.2013.819511

Leary, M. R., \& Kowalski, R. M. (1993). The Interaction Anxiousness Scale: Construct and criterionrelated validity. Journal of Personality Assessment, 61, 136-146.

Lee-Won, R. J., Herzog, L., \& Park, S. G. (2015). Hooked on Facebook: The role of social anxiety and need for social assurance in problematic use of Facebook. Cyberpsychology, Behavior, and Social Networking, 18, 567-574. https://doi.org/10.1089/cyber.2015.0002

Lin, C.-Y. (2020). Social reaction toward the 2019 novel coronavirus (COVID-19). Social Health and Behavior, 3(1), 1-2. https://doi.org/10.4103/SHB.SHB_11_20

Lin, C.-Y., Broström, A., Nilsen, P., Griffiths, M. D., \& Pakpour, A. H. (2017). Psychometric validation of the Persian Bergen Social Media Addiction Scale using classic test theory and Rasch models. Journal of Behavioral Addictions, 6(4), 620-629. https://doi.org/10.1556/2006.6.2017.071

Lin, C.-Y., Lin, C. K., Imani, V., Griffiths, M. D., \& Pakpour, A. H. (2019). Evaluation of the selfitis behavior scale across two Persian-speaking countries, Iran and Afghanistan: Advanced psychometric testing in a large-scale sample. International Journal of Mental Health and Addiction. https:// doi.org/10.1007/s11469-019-00124-y

LISREL 9. (2019). Scientific Software International, Inc.

Longstreet, P., \& Brooks, S. (2017). Life satisfaction: A key to managing internet \& social media addiction. Technology in Society, 50, 73-77. https://doi.org/10.1016/j.techsoc.2017.05.003 
Luo, T., Qin, L., Cheng, L., Wang, S., Zhu, Z., Xu, J., Chen, H., Liu, Q., Hu, M., Tong, J., Hao, W., \& Liao, Y. (2021). Determination the cut-off point for the Bergen social media addiction (BSMAS): Diagnostic contribution of the six criteria of the components model of addiction for social media disorder. Journal of Behavioral Addictions, 10(2), 281-290. https://doi.org/10.1556/2006.2021.00025

Lyubomirsky, S., \& Lepper, H. (1999). A measure of subjective happiness: Preliminary reliability and construct validation. Social Indicators Research, 46, 137-155.

McDonald, R. P. (1999). Test theory: A unified treatment. Lawrence Erlbaum.

Meshi, D., Cotton, S. R., \& Bender, A. R. (2020). Problematic social media use and perceived social isolation in older adults: A cross-sectional study. Gerontology, 66, 160-168. https://doi.org/10.1159/00050 2577

Monacis, L., De Palo, V., Griffiths, M. D., \& Sinatra, M. (2017). Social networking addiction, attachment style, and validation of the Italian version of the Bergen Social Media Addiction Scale. Journal of Behavioral Addictions, 6(2), 178-186.

Monacis, L., Griffiths, M. D., Limone, P., Sinatra, M., \& Servidio, R. (2020). Selfitis behavior: Assessing the Italian version of the selfitis behavior scale and its mediating role in the relationship of dark traits with social media addiction. International Journal of Environmental Research and Public Health, 17, 5738. https://doi.org/10.3390/ijerph17165738

Panno, A., Carbone, G. A., Massullo, C., Farina, B., \& Imperatori, C. (2020). COVID-19 related distress is associated with alcohol problems, social media and food addiction symptoms: Insights from the Italian experience during the lockdown. Frontiers in Psychiatry, 11,. https://doi.org/10.3389/fpsyt.2020. 577135

Pituch, K. A., \& Stevens, J. P. (2016). Applied multivariate statistics for the social sciences analyses with SAS and IBM's SPSS (6th ed.). Routledge Taylor \& Frances Group.

RStudio Team (2020). RStudio: Integrated Development for R. RStudio, PBC, Boston, MA http://www.rstud io.com/.

Rosenberg, M. (1965). Society and the adolescent self-image. Princeton University Press.

Satici, S. A., \& Uysal, R. (2015). Well-being and problematic Facebook use. Computers in Human Behavior, 49, 185-190. https://doi.org/10.1016/j.chb.2015.03.005

Shensa, A., Escobar-Viera, C. G., Sidani, J. E., Bowman, N. D., Marshal, M. P., \& Primack, B. A. (2017). Problematic social media use and depressive symptoms among US young adults: A nationally-representative study. Social Science \& Medicine, 182, 150-157. https://doi.org/10.1016/j.socscimed.2017. 03.061

Sousa, V. D., \& Rojjanasrirat, W. (2011). Translation, adaptation and validation of instruments or scales for use in cross-cultural health care research: A clear and user-friendly guideline. Journal of Evaluation in Clinical Practice, 17, 268-274. https://doi.org/10.1111/j.1365-2753.2010.01434.x

StataCorp LLC. (2020). Stata®16.1 Statistics. Data analysis. Statistical Software. College Station, TX: StataCorp LLC.

Toma, C. L., Chen, A. Y., Olson, C., Fan, T., \& Brown, B. B. (2020). Youth Social Media Use and WellBeing. In J. V. den Bulck (Ed.), The Internationcal Encyclopedia of Media Psychology (pp. 1-10). Wiley-Blackwell. https://doi.org/10.1002/9781119011071.iemp0210

Varchetta, M., Fraschetti, A., Mari, E., \& Giannini, A. M. (2020). Social Media Addiction, Fear of Missing Out (FoMO) and Online Vulnerability in university students. Revista Digital de Investigación en Docencia Universitaria, 14(1), e1187. https://doi.org/10.19083/ridu.2020.1187

Watson, J. C., Prosek, E. A., \& Giordano, A. L. (2020). investigating psychometric properties of social media addiction measures among adolescents. Journal of Counselling \& Development, 98, 458-466. https://doi.org/10.1002/jcad.12347

Wong, H. Y., Mo, H. Y., Potenza, M. N., Chan, M. N., Lau, W. M., Chui, T. K., Pakpour, A. H., \& Lin C. Y. (2020). Relationships between severity of internet gaming disorder, severity of problematic social media use, sleep quality and psychological distress. International Journal of Environmental Research and Public Health, 17, 1879; https://doi.org/10.3390/ijerph17061879

Worsley, J., Mansfield, R., \& Corcoran, R. (2018). Attachment anxiety and problematic social media use: The mediating role of well-Being. Cyberpsychology, Behavior, and Social Networking, 21(9), $563-568$.

Publisher's Note Springer Nature remains neutral with regard to jurisdictional claims in published maps and institutional affiliations. 